\title{
Non-Linear Buckling Analysis of Axially Loaded Column with Non-Prismatic I-Section
}

\author{
Adrian P Dharma* and Bambang Suryoatmono \\ Department of Civil Engineering, Parahyangan Catholic University, Bandung, INDONESIA \\ "Corresponding authors: adrianpramudita09@gmail.com \\ SUBMITTED 13 July 2019 REVISED 28 August 2019 ACCEPTED 30 August 2019
}

\begin{abstract}
In order to use material efficiently, non-prismatic column sections are frequently employed. Tapered-web column cross-sections are commonly used, and design guides of such sections are available. In this study, various web-and-flange-tapered column sections were analysed numerically using finite element method to obtain each buckling load assuming the material as elastic-perfectly plastic material. For each non-prismatic column, the analysis was also performed assuming the column is prismatic using average cross-section with the same length and boundary conditions. Buckling load of the prismatic columns were obtained using equation provided by AISC 360-16. This study proposes a multiplier that can be applied to the buckling load of a prismatic column with an average cross-section to acquire the buckling load of the corresponding non-prismatic column. The multiplier proposed in this study depends on three variables, namely the depth tapered ratio, width tapered ratio, and slenderness ratio of the prismatic section. The equation that uses those three variables to obtain the multiplier is obtained using regression of the finite element results with a coefficient of determination of 0.96 .
\end{abstract}

KEYWORDS Non-prismatic column; Web-and-flange-tapered; Flexural buckling; Non-linear buckling

(c) The Author(s) 2019. This article is distributed under a Creative Commons Attribution-ShareAlike 4.0 International license.

\section{INTRODUCTION}

\subsection{Background}

Zieman (2010) states that the non-prismatic column or tapered column is a column that has a continuously varying cross-section along its length. The reason behind the application of such a column section is to use material efficiently and increasing its load-carrying capacity. Nowadays tapered-web sections are frequently used in steel structures. Usually, the tapered web column is made by integrate 3 plates for its web and flanges.

Timoshenko and Gere (1963) proposed an analytical solution of the buckling load of linearly tapered-web cantilevered column expressed in Equation (1) assuming that the variation of moment of inertia is to the $n^{\text {th }}$-power along the column length.

$P_{c r}=\frac{m E I_{\max }}{L^{2}}$

where $E$ is the material modulus of elasticity, $I_{\max }$ is the maximum moment of inertia of the column,
$L$ is column length, and $m$ is a constant that depends on $n$ and the ratio of the minimum moment of inertia of the section to the maximum one.

Lee et al. (1972) propose an equation of buckling load to tapered-web column as expressed in Equation (2). In order to acquire the buckling load of such column, that equation employs an equivalent length of prismatic column with the smallest cross-section along its length.

$P_{c r}=\frac{E I_{\min }}{(g L)^{2}}$

where $g$ is the equivalent length factor expressed in Equation (3) and $I_{\min }$ is the minimum moment of inertia of the column.

$g=1-0.375 \gamma+0.080 \gamma^{2}(1-0.075 \gamma)$

and $\gamma=\frac{d_{b}}{d_{t}}$

where $d_{b}$ is larger depth and $d_{t}$ is smaller depth of the column section. 
Ibrahim (2017) purpose elastic buckling load of tapered-web column as expressed in Equation (5). In order to acquire elastic buckling load, that equation employs buckling load factor. Buckling load factor depend on ratio between maximum and minimum of the moment inertia and support condition of the column.

$P_{c r}=\gamma_{c r} \frac{E I}{(L)^{2}}$

Where $I$ is moment inertia of the prismatic column, $\gamma_{\mathrm{cr}}$ is the buckling load factor which depends on the ratio of moment inertia and support condition of the column.

Riahi et al. (2012) purpose elastic buckling load of tapered-web column is expressed in Equation (6). Equation (6) employs length factor of the column to calculate elastic buckling load of tapered-web column.

$P_{c r}=\frac{E I_{\min }}{\left(\kappa_{\gamma} L\right)^{2}}$

Where $\kappa_{\gamma}$ is length factor expressed in Equation (7)

$\kappa_{\gamma}=\frac{1}{\eta \sqrt{\mu^{2}+\frac{1}{4}}}$

Where $\eta$ is section constant and $\mu$ is load constant.

In Eurocode (2005), the buckling load of nonprismatic cross-section needs to be determined by second-order analysis. However, based on their research, Marques et al. (2014) conclude that second-order analysis is not reliable, and iteration formula for prismatic section is proposed for tapered-web column.

Tanakova et al. (2017) analysed tapered-web columns numerically, experimentally, and analytically and compared the results. The dimensions of three columns and one beamcolumn analysed are shown in Table 2 . Column means the member is subjected to axial load. Beam-column means the member is subjected to axial and moment load at the same time. The members consist of two types of shape, L-shape and V-shape as shown in Figure 1.
In the analytical procedure, they used Eurocode (2005) and adapted the iteration formula for tapered-web proposed by Marques et al. to obtain buckling load and compared the results with the numerical and experimental results as shown in Table 1.

Kucukler and Gardner (2018) proposed stiffness reduction method to acquire buckling load of tapered-web member. The reduction factor is defined based on the type of loading and the ratio of applied load to the plastic capacity of the corresponding loading type.

Analysis using the stiffness reduction method consists of 4 steps. First, the column is divided into small segments with appropriate prismatic sections. Second, the stiffness reduction factor of each segment is calculated based on the applied load. Third, geometrically non-linear analysis of the segmented member with reduced stiffness is performed. Finally, cross-section strength is checked.

AISC 360-16 provides a critical axial load for prismatic column section due to buckling failure based on SSRC Curve 2. Bjorhovde, R (1972) proposed SSRC Curve 2 that shows the ratios between the buckling load to the plastic capacity of the column with initial out-of-straightness $\mathrm{L} / 1000$ for every slenderness ratio as seen in Equation (8).

$\lambda=\frac{1}{\pi} \sqrt{\frac{F_{y}}{E}} \frac{L}{r}$

where $F_{y}$ is yield stress of the material and $r$ is radius of gyration of the prismatic column section.

Table 1. Experimental, numerical, and analytical buckling loads obtained by Tanakova et al. (2017)

\begin{tabular}{llll}
\hline Test & $\begin{array}{l}\text { Experimental } \\
(\mathrm{kN})\end{array}$ & $\begin{array}{l}\text { Numerical } \\
(\mathrm{kN})\end{array}$ & $\begin{array}{l}\text { Analytical } \\
(\mathrm{kN})\end{array}$ \\
\hline $\mathrm{C} 1$ & 1397.6 & 1393.0 & 1311.7 \\
$\mathrm{C} 2$ & 1313.6 & 1289.9 & 1172.9 \\
$\mathrm{C} 3$ & 1460.0 & 1449.4 & 1244.8 \\
$\mathrm{BC}$ & 379 & 386.9 & 275 \\
\hline
\end{tabular}


Table 2. Dimension in experimental analysis by Tanakova et al (2017)

\begin{tabular}{lllllllllll}
\hline Test & $\gamma$ & Shape & $\begin{array}{l}d_{t} \\
(\mathrm{~mm})\end{array}$ & $\begin{array}{l}d_{b} \\
(\mathrm{~mm})\end{array}$ & $\begin{array}{l}b_{t} \\
(\mathrm{~mm})\end{array}$ & $\begin{array}{l}b_{b} \\
(\mathrm{~mm})\end{array}$ & $\begin{array}{l}t_{w} \\
(\mathrm{~mm})\end{array}$ & $\begin{array}{l}t_{\text {ftop }} \\
(\mathrm{mm})\end{array}$ & $\begin{array}{l}t_{\text {fbot }} \\
(\mathrm{mm})\end{array}$ & $\begin{array}{l}L \\
(\mathrm{~m})\end{array}$ \\
\hline $\mathrm{C} 1$ & 4 & $\mathrm{~V}$ & 120 & 480 & 100 & 100 & 12 & 12 & 12 & 6 \\
$\mathrm{C} 2$ & 2 & $\mathrm{~V}$ & 185 & 370 & 110 & 110 & 6 & 12 & 12 & 6 \\
$\mathrm{C} 3$ & 3 & $\mathrm{~L}$ & 120 & 360 & 100 & 100 & 10 & 16 & 16 & 6 \\
$\mathrm{BC}$ & 3 & $\mathrm{~L}$ & 120 & 360 & 100 & 100 & 10 & 16 & 16 & 6 \\
\hline
\end{tabular}

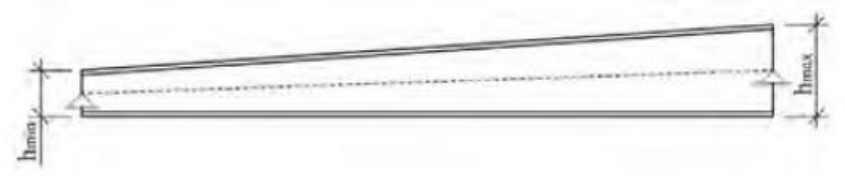

Figure 1. a) Tapered L-shape member (Left); b) tapered Vshape member (Right) by Tanakova et al (2017)

Salmon et al. (2009) state AISC 360-16 substitutes initial out-of-straightness and slenderness ratio by Bjorhovde (1972) to L/1500 for initial out-ofstraightness and slenderness ratio as expressed in Equation (9). AISC 360-16 provides equations for flexural-, torsional-, and local- buckling loads. Flexural buckling load of non-slender element is given by Equation (10) and (11).

$\lambda=\frac{K L}{r}$

$P_{c r}=\left(0.658^{\frac{F_{e}}{F_{y}}}\right) F_{y} A_{g}$ for $F_{e} \geqslant 0.44 F_{y}$

$P_{c r}=0.877 F_{e} A_{g}$ for $F_{e}<0.44 F_{y}$

Where $F_{e}$ is elastic buckling stress expressed in Equation (12).

$F_{e}=\frac{\pi^{2} E I}{\left(\frac{k L}{r}\right)^{2}}$

where $A_{g}$ is gross section area of the column and $K$ is effective length factor ( $K=1$ for simply supported column).

Kaehler et al. (2011) state that tapered-web column sections have much more major axis buckling strength but only slightly more minor axis buckling strength compared to prismatic section with the smallest cross-section along its length. Buckling strength is affected by moment of inertia linearly. Tapering the depth of the section increases the major axis moment of inertia significantly, but the minor axis moment of inertia is nearly constant. Therefore, the buckling strength of tapered-web column in its minor axis is usually assumed to be the same as for prismatic section.

AISC 360-16 does not provide calculation to obtain buckling load of web-and-flange-tapered section. In this study, non-prismatic web-andflange-tapered column sections are analysed numerically. This study proposes multiplier that can be applied to the buckling load of prismatic column with an average cross section along its length to obtain buckling load of the corresponding tapered-web-and-flange column section. Buckling load of prismatic column is computed using the equations in AISC 360-16.

\subsection{Parameter Study}

In this study finite element method is used to obtain buckling load of non-prismatic web-andflange-tapered column section. Finite element method requires defined parameters to analyse the problem. The parameters are geometry of the column, element type meshing in modelling process, axial load, and boundary conditions.

Tapered ratios of non-prismatic column section, $d_{t} / d_{b}$ and $b_{t} / b_{b}$, are shown in Table 3. Symbols $d$ and $b$ represent depth and width of the cross section, respectively. Subscripts $t$ and $b$ represent the top and bottom of the column, respectively. Using the maximum section dimension as 500 $\mathrm{mm} \times 500 \mathrm{~mm}$ in the bottom of the column and based on given tapered ratios, non-prismatic column cross-section dimensions are shown in Table 4 with flange thickness of $18 \mathrm{~mm}$ and web thickness of $15 \mathrm{~mm}$. Column is made of steel with yield stress of $250 \mathrm{MPa}$ and the material is assumed to be in an elastic-perfectly plastic. 
The column is simply supported with roller support at the top and hinge at the bottom. Translation in $\mathrm{X}$ and $\mathrm{Z}$ directions are prohibited to model the roller. Translation in $\mathrm{X}, \mathrm{Y}$, and $\mathrm{Z}$ directions are prohibited to model hinge behaviour. Both top and bottom cross sections are prevented from twisting. Axial loading is given at the top of the column where the vertical translation is possible. See Figure 3 for loading and boundary conditions and the definition of the axes.

Table 3. Tapered ratio of non-prismatic tapered-weband-flange column

\begin{tabular}{lll}
\hline$d_{t} / d_{b}$ & $b_{t} / b_{b}$ & $L(\mathrm{~m})$ \\
\hline 0.3 & 0.3 & 6 \\
0.3 & 0.3 & 7 \\
0.3 & 0.3 & 8 \\
0.3 & 0.5 & 6 \\
0.3 & 0.5 & 7 \\
0.3 & 0.5 & 8 \\
0.3 & 0.7 & 6 \\
0.3 & 0.7 & 7 \\
0.3 & 0.7 & 8 \\
0.5 & 0.3 & 6 \\
0.5 & 0.3 & 7 \\
0.5 & 0.3 & 8 \\
0.5 & 0.5 & 6 \\
0.5 & 0.5 & 7 \\
0.5 & 0.5 & 8 \\
0.5 & 0.7 & 6 \\
0.5 & 0.7 & 7 \\
0.5 & 0.7 & 8 \\
0.7 & 0.3 & 6 \\
0.7 & 0.3 & 7 \\
0.7 & 0.3 & 8 \\
0.7 & 0.5 & 6 \\
0.7 & 0.5 & 7 \\
0.7 & 0.5 & 8 \\
0.7 & 0.7 & 6 \\
0.7 & 0.7 & 7 \\
0.7 & 0.7 & 8 \\
\hline
\end{tabular}

SHELL281

3-D Structural 8-Node Finite Strain Layered Shell 8 nodes $3-D$ space

DOF:UX, UY, UZ, ROTX, ROTY, ROTZ

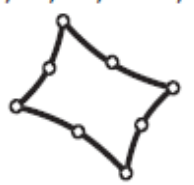

Figure 2. Shell281 as defined in Element Reference ANSYS Release 11.0 (2007)

Table 4. Column Dimensions

\begin{tabular}{llll}
\hline $\begin{array}{l}d_{t} \times b_{t} \\
(\mathrm{~mm})\end{array}$ & $\begin{array}{l}d_{\text {avg }} \times b_{\text {avg }} \\
(\mathrm{mm})\end{array}$ & $\begin{array}{l}d_{b} \times b_{b} \\
(\mathrm{~mm})\end{array}$ & $L(\mathrm{~m})$ \\
\hline $150 \times 150$ & $325 \times 325$ & $500 \times 500$ & 6 \\
$150 \times 150$ & $325 \times 325$ & $500 \times 500$ & 7 \\
$150 \times 150$ & $325 \times 325$ & $500 \times 500$ & 8 \\
$150 \times 250$ & $325 \times 375$ & $500 \times 500$ & 6 \\
$150 \times 250$ & $325 \times 375$ & $500 \times 500$ & 7 \\
$150 \times 250$ & $325 \times 375$ & $500 \times 500$ & 8 \\
$150 \times 350$ & $325 \times 425$ & $500 \times 500$ & 6 \\
$150 \times 350$ & $325 \times 425$ & $500 \times 500$ & 7 \\
$150 \times 350$ & $325 \times 425$ & $500 \times 500$ & 8 \\
$250 \times 150$ & $375 \times 325$ & $500 \times 500$ & 6 \\
$250 \times 150$ & $375 \times 325$ & $500 \times 500$ & 7 \\
$250 \times 150$ & $375 \times 325$ & $500 \times 500$ & 8 \\
$250 \times 250$ & $375 \times 375$ & $500 \times 500$ & 6 \\
$250 \times 250$ & $375 \times 375$ & $500 \times 500$ & 7 \\
$250 \times 250$ & $375 \times 375$ & $500 \times 500$ & 8 \\
$250 \times 350$ & $375 \times 425$ & $500 \times 500$ & 6 \\
$250 \times 350$ & $375 \times 425$ & $500 \times 500$ & 7 \\
$250 \times 350$ & $375 \times 425$ & $500 \times 500$ & 8 \\
$350 \times 150$ & $425 \times 325$ & $500 \times 500$ & 6 \\
$350 \times 150$ & $425 \times 325$ & $500 \times 500$ & 7 \\
$350 \times 150$ & $425 \times 325$ & $500 \times 500$ & 8 \\
$350 \times 250$ & $425 \times 375$ & $500 \times 500$ & 6 \\
$350 \times 250$ & $425 \times 375$ & $500 \times 500$ & 7 \\
$350 \times 250$ & $425 \times 375$ & $500 \times 500$ & 8 \\
$350 \times 350$ & $425 \times 425$ & $500 \times 500$ & 6 \\
$350 \times 350$ & $425 \times 425$ & $500 \times 500$ & 7 \\
$350 \times 350$ & $425 \times 425$ & $500 \times 500$ & 8 \\
\hline & & &
\end{tabular}


A: Static Structural

Static Structura

Time: 1.s

6/17/2019 5:12 AM

A $R y=0$

B] $R y=0$

C) Py: $1000 . \mathrm{N}$

D Ry: $0{ }^{\circ}$

ERy: $0{ }^{\circ}$

[F] $\cup X, \cup Z=0$

G $\cup X, \cup Y, \cup Z=0$
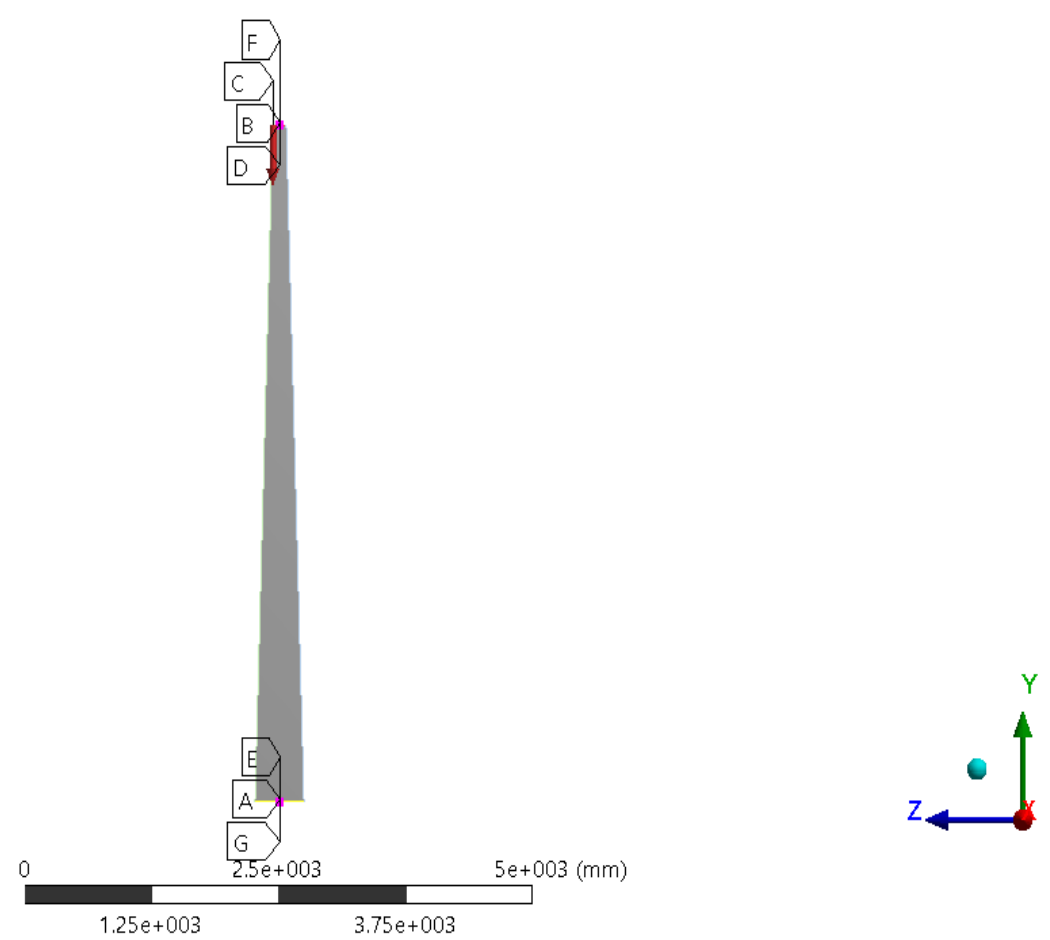

first buckling mode of linear buckling analysis is shown in Figure 4.

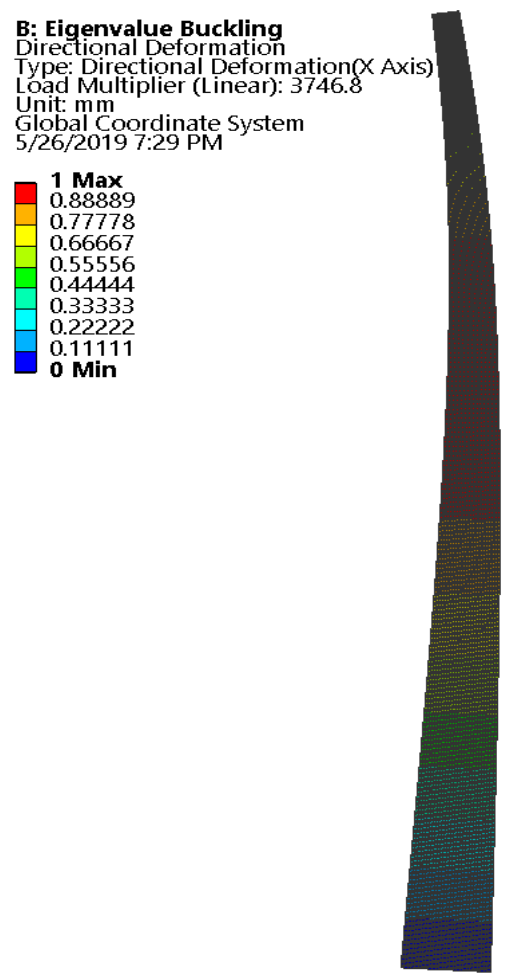

Figure 4. Typical first buckling mode 


\section{ANALYSIS AND DISCUSSION}

\subsection{Model Verification}

Buckling load from finite element analysis (FEA) needs to be verified to ensure that all parameters in the finite element model is proper. First, prismatic column section is modelled to check the linear buckling load of prismatic column. Dimension of prismatic column, linear buckling load from FEA, and Euler's buckling load $P_{e}$ is shown in Table 6. Table 6 shown that linear buckling load of FEA is close to Euler's buckling load, less than $2 \%$ of error. Therefore, the parameters in the FEA is verified.

Third, C1 column by Tanakova et al. (2017) as shown in Table 2 is remodelled with element type and mesh size as mention in Section 1.2, while yield stress of the material is $370 \mathrm{MPa}$ according to Tanakova et al. (2017). Non-linear buckling load obtained from non-linear analysis of the remodelled column and buckling load gap to $\mathrm{C} 1$ column by Tanakova et al. (2017) is shown in Table 5. Table 5 shows that differential of buckling load is $-1.83 \%$. Therefor the parameters in the FEA is verified.

Second, buckling load of non-prismatic tapered web-and-flange section from FEA and critical load of prismatic section computed using AISC 360-16 for every average slenderness ratio $K L / r$ are plotted in Figure 5.
The average slenderness ratio in the figure means slenderness ratio $K L / r$ of prismatic column computed using radius of gyration $r$ of the cross section using average width and average depth of the top and bottom cross sections. Therefore, the buckling load of non-prismatic section for any average slenderness ratio must be between the buckling load of maximum and minimum cross sections and this requirement is met as seen in Figure 5. Therefore, the parameters in the FEA is verified.

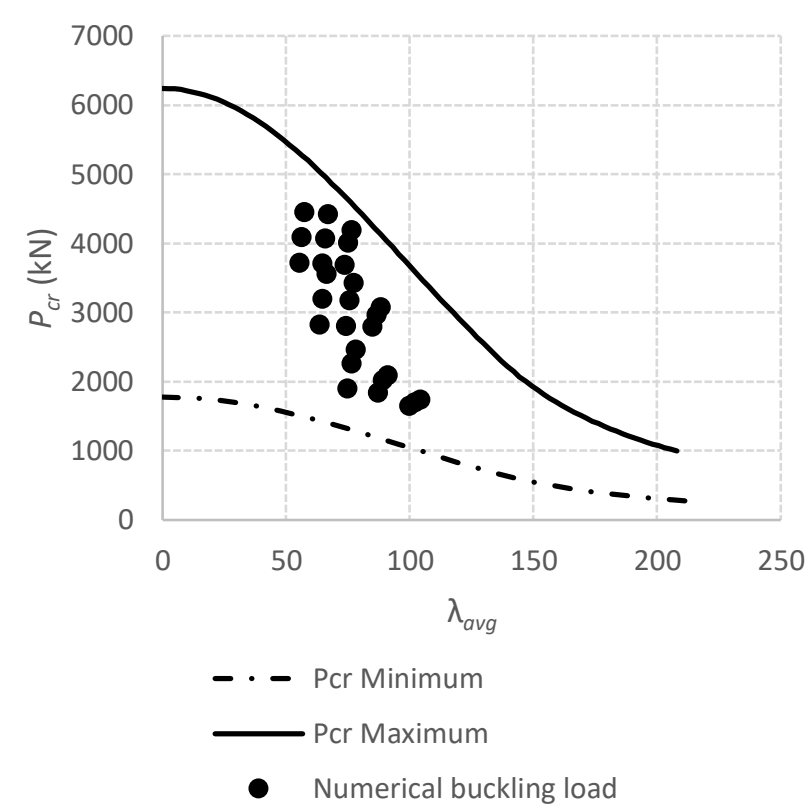

Figure 5. Buckling load of upper bound, lower bound, and non-prismatic column section

Table 5. Remodelled and experimental buckling load of C1 column) for verification purpose

\begin{tabular}{lllllllllll}
\hline $\begin{array}{l}d_{t} \\
(\mathrm{~mm})\end{array}$ & $\begin{array}{l}d_{b} \\
(\mathrm{~mm})\end{array}$ & $\begin{array}{l}b_{t} \\
(\mathrm{~mm})\end{array}$ & $\begin{array}{l}b_{b} \\
(\mathrm{~mm})\end{array}$ & $\begin{array}{l}t_{w} \\
(\mathrm{~mm})\end{array}$ & $\begin{array}{l}t_{f . t o p} \\
(\mathrm{~mm})\end{array}$ & $\begin{array}{l}t_{f . b o t} \\
(\mathrm{~mm})\end{array}$ & $\begin{array}{l}L \\
(\mathrm{~m})\end{array}$ & $\begin{array}{l}P_{\text {cr }} \\
\text { Experimental } \\
(\mathrm{kN})\end{array}$ & $\begin{array}{l}P_{c r F E A} \\
(\mathrm{kN})\end{array}$ & $\begin{array}{l}\Delta P_{c r} \\
(\%)\end{array}$ \\
\hline 120 & 480 & 100 & 100 & 12 & 12 & 12 & 6 & 1397.6 & 1372 & -1.83 \\
\hline
\end{tabular}

Table 6. Verification prismatic column to Euler's Buckling Load

\begin{tabular}{lllll}
\hline Cross section $(\mathrm{mm})$ & $L(\mathrm{~m})$ & $P_{e}(\mathrm{kN})$ & $P_{\text {crFEAEl }}(\mathrm{kN})$ & $\Delta P_{\text {crFEAEL }}(\%)$ \\
\hline $150 \times 150 \times 15 \times 18$ & 6 & 556.92 & 555.24 & -0.30 \\
$500 \times 500 \times 15 \times 18$ & 8 & 11569 & 11367 & -1.75 \\
\hline
\end{tabular}


Table 7. Buckling load $P_{C r F E A}$ and maximum lateral displacement $\Delta_{\max }$

\begin{tabular}{lllll}
\hline$b_{t} / b_{b}$ & $d_{t} / d_{b}$ & $\lambda_{\text {avg }}$ & $\begin{array}{l}P_{\text {crFEA }} \\
(\mathrm{kN})\end{array}$ & $\begin{array}{l}\Delta_{\max } \\
(\mathrm{mm})\end{array}$ \\
\hline 0.3 & 0.3 & 74.84 & 1902 & 4.2326 \\
0.3 & 0.3 & 87.31 & 1835 & 9.1801 \\
0.3 & 0.3 & 99.79 & 1647 & 19.926 \\
0.3 & 0.5 & 76.56 & 2260 & 6.6275 \\
0.3 & 0.5 & 89.32 & 2015 & 13.996 \\
0.3 & 0.5 & 102.09 & 1701 & 22.715 \\
0.3 & 0.7 & 78.25 & 2462 & 8.93 \\
0.3 & 0.7 & 91.29 & 2087 & 14.906 \\
0.3 & 0.7 & 104.33 & 1736 & 24.923 \\
0.5 & 0.3 & 63.69 & 2819 & 3.1243 \\
0.5 & 0.3 & 74.30 & 2801 & 4.9538 \\
0.5 & 0.3 & 84.92 & 2796 & 10.978 \\
0.5 & 0.5 & 65.01 & 3192 & 3.1282 \\
0.5 & 0.5 & 75.85 & 3171 & 7.1753 \\
0.5 & 0.5 & 86.68 & 2966 & 15.471 \\
0.5 & 0.7 & 66.31 & 3559 & 4.0257 \\
0.5 & 0.7 & 77.36 & 3423 & 9.7155 \\
0.5 & 0.7 & 88.41 & 3073 & 16.92 \\
0.7 & 0.3 & 55.39 & 3716 & 1.9738 \\
0.7 & 0.3 & 64.62 & 3703 & 3.5435 \\
0.7 & 0.3 & 73.86 & 3687 & 6.4792 \\
0.7 & 0.5 & 56.44 & 4086 & 2.2132 \\
0.7 & 0.5 & 65.84 & 4070 & 4.2065 \\
0.7 & 0.5 & 75.25 & 4010 & 8.3642 \\
0.7 & 0.7 & 57.47 & 4449 & 2.4842 \\
0.7 & 0.7 & 67.04 & 4422 & 6.6661 \\
0.7 & 0.7 & 76.62 & 4184 & 11.485 \\
\hline & & & &
\end{tabular}

\subsection{Buckling Load}

FEA in this study shows that flexural buckling of weak axis occurs in all tapered web-and-flange column sections. FEA is stopped when the nonprismatic column is not able to withstand any additional load. Buckling load of every column is displayed in Table 7. According to AL-Shareef (2014), larger width and depth ratio has greater tapered buckling load capacity. Flexural buckling of weak axis depends on moment of inertia of the weak axis and width of the section affect the weak moment of inertia much more than depth of the section. Therefore, width tapered ratio has much more effects on buckling load than depth tapered ratio and it happens in this study, as excepted.

Table 8 shows that as width tapered ratio increases from 0.3 to 0.7 for every depth tapered ratio and column length, the buckling load increases between $80.7 \%$ to $141.1 \%$. Table 9 shows that as depth tapered ratio increases from 0.3 to 0.7 for every width tapered ratio and column length, the buckling load increases between $5.4 \%$ to $29.4 \%$.

Table 8. Buckling load for increasing tapered-width ratio

\begin{tabular}{lllll}
\hline$b_{t} / b_{b}$ & $d_{t} / d_{b}$ & $\mathrm{~L}(\mathrm{~m})$ & $\lambda_{\text {avg }}$ & $\begin{array}{l}P_{\text {crFEA }} \\
(\mathrm{kN})\end{array}$ \\
\hline 0.3 & 0.3 & 6 & 74.84 & 1902 \\
0.7 & 0.3 & 6 & 55.39 & 3716 \\
0.3 & 0.5 & 6 & 76.56 & 2260 \\
0.7 & 0.5 & 6 & 56.44 & 4086 \\
0.3 & 0.7 & 6 & 78.25 & 2462 \\
0.7 & 0.7 & 6 & 57.47 & 4449 \\
0.3 & 0.3 & 7 & 87.31 & 1835 \\
0.7 & 0.3 & 7 & 64.62 & 3703 \\
0.3 & 0.5 & 7 & 89.32 & 2015 \\
0.7 & 0.5 & 7 & 65.84 & 4070 \\
0.3 & 0.7 & 7 & 91.29 & 2087 \\
0.7 & 0.7 & 7 & 67.04 & 4422 \\
0.3 & 0.3 & 8 & 99.79 & 1647 \\
0.7 & 0.3 & 8 & 73.86 & 3687 \\
0.3 & 0.5 & 8 & 102.09 & 1701 \\
0.7 & 0.5 & 8 & 75.25 & 4010 \\
0.3 & 0.7 & 8 & 104.33 & 1736 \\
0.7 & 0.7 & 8 & 76.62 & 4184 \\
\hline
\end{tabular}

Table 9. Buckling load for increasing tapered-depth ratio

\begin{tabular}{lllll}
\hline$b_{t} / b_{b}$ & $d_{t} / d_{b}$ & $\mathrm{~L}(\mathrm{~m})$ & $\lambda_{\text {avg }}$ & $\begin{array}{l}P_{\text {crFEA }} \\
(\mathrm{kN})\end{array}$ \\
\hline 0.3 & 0.3 & 6 & 74.84 & 1902 \\
0.3 & 0.7 & 6 & 78.25 & 2462 \\
0.5 & 0.3 & 6 & 63.69 & 2819 \\
0.5 & 0.7 & 6 & 66.31 & 3559 \\
0.7 & 0.3 & 6 & 55.36 & 3716 \\
0.7 & 0.7 & 6 & 57.47 & 4449 \\
0.3 & 0.3 & 7 & 87.31 & 1835 \\
0.3 & 0.7 & 7 & 91.29 & 2087 \\
0.5 & 0.3 & 7 & 74.30 & 2801 \\
0.5 & 0.7 & 7 & 77.36 & 3423 \\
0.7 & 0.3 & 7 & 64.62 & 3703 \\
0.7 & 0.7 & 7 & 67.04 & 4422 \\
0.3 & 0.3 & 8 & 99.79 & 1647 \\
0.3 & 0.7 & 8 & 104.33 & 1736 \\
0.5 & 0.3 & 8 & 84.92 & 2796 \\
0.5 & 0.7 & 8 & 88.41 & 3073 \\
0.7 & 0.3 & 8 & 73.86 & 3687 \\
0.7 & 0.7 & 8 & 76.62 & 4184 \\
\hline
\end{tabular}




\subsection{Lateral Deflection}

Width tapered ratio, depth tapered ratio, and column length govern the slenderness ratio of the column. Column with large width tapered ratio has smaller slenderness ratio. Column with large depth tapered ratio has larger slenderness ratio. Short column has smaller slenderness ratio. Slenderness ratio of the column determines not only the buckling load but also the lateral deflection of the column during buckling. Slender column tends to deflect more easily than stocky column. FEA results in this study show that column with larger slenderness ratio has larger lateral deflection, as shown in Table 7 .

\subsection{Rigidity}

Rigidity of non-prismatic columns can be observed from the slope of the gradient of axial load versus lateral displacement curve. To analyse rigidity of the column, axial load versus lateral displacement curve for every column length is plotted in Figure 6, 7, and 8. As seen in those figures, column with larger buckling load has smaller lateral displacement and larger rigidity. Increasing width tapered ratio increases column rigidity significantly. On the other hand, increasing depth tapered ratio only slightly increases rigidity of the column. This is because flexural buckling happens in the weak axis and depth tapered ratio does not affect significantly moment of inertia in that direction.

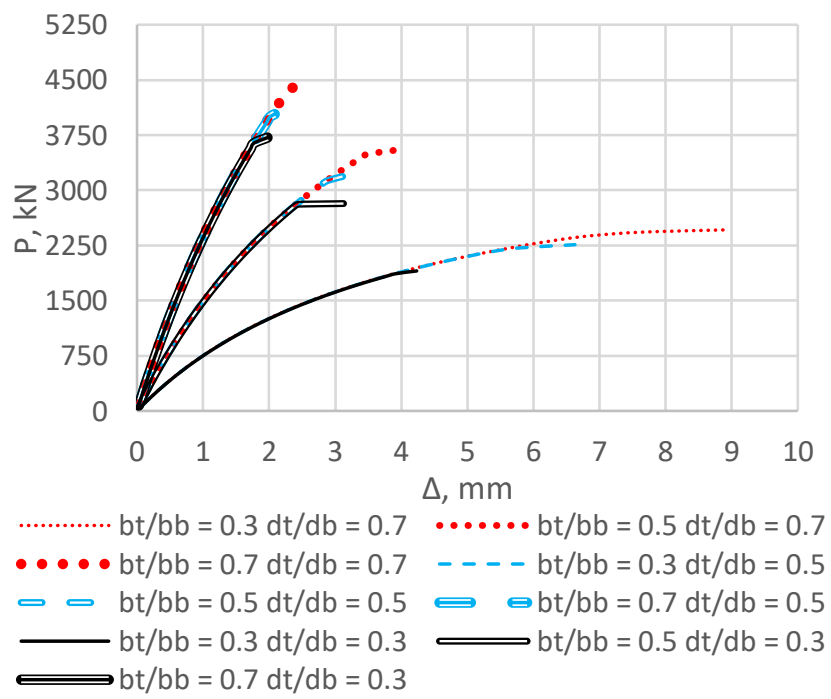

Figure 6. Axial load versus lateral displacement curves for $L$ $=6 \mathrm{~m}$

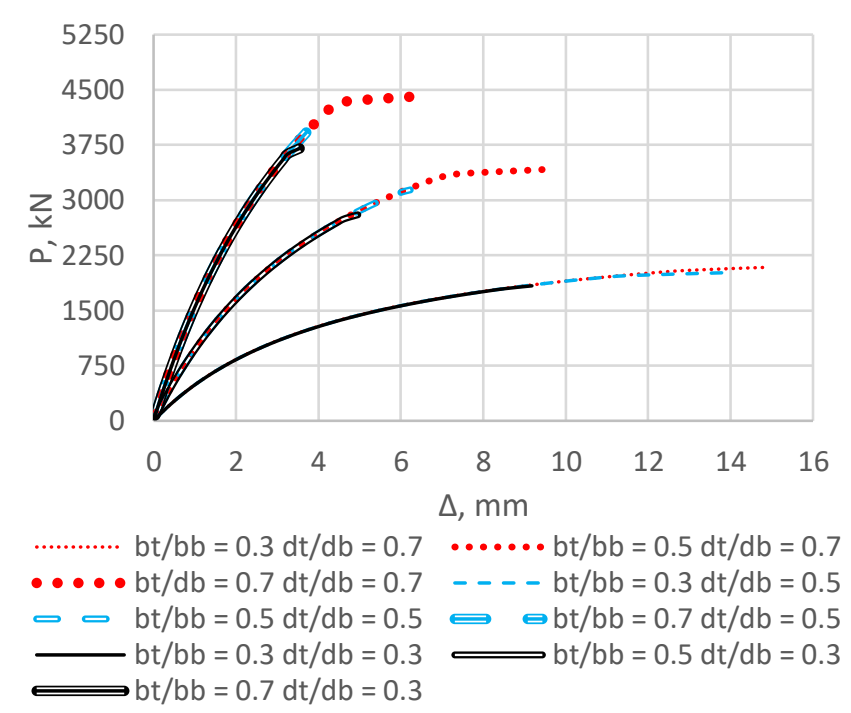

Figure 7. Axial load versus lateral displacement curves for $L$ $=7 \mathrm{~m}$

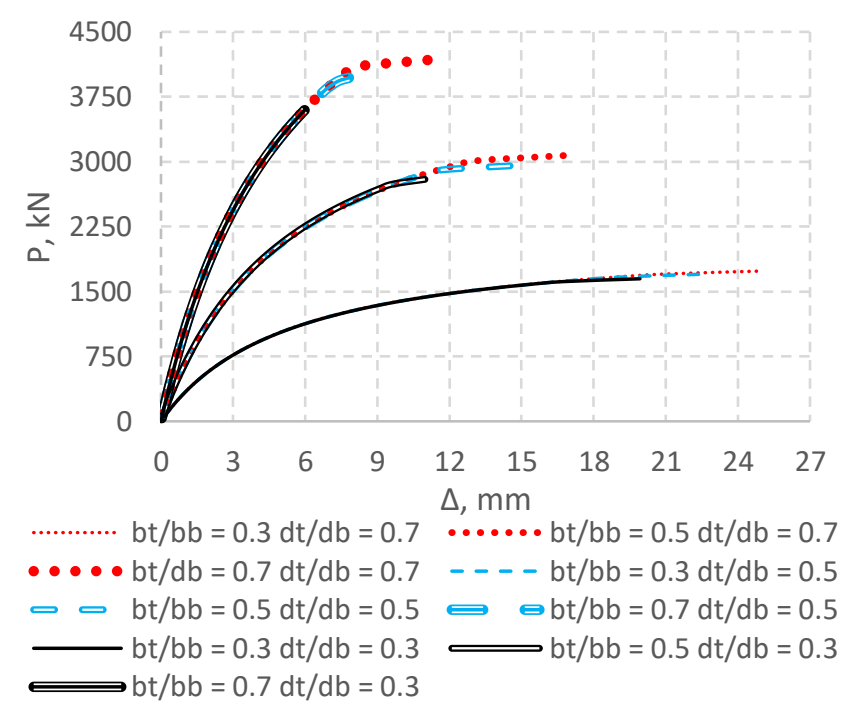

Figure 8. Axial load versus lateral displacement curves for $L$ $=8 \mathrm{~m}$

Length of the column also affects its rigidity. To analyse rigidity of the column in terms of column length, axial load versus lateral displacement curve of every column with different length is plotted in Figure 9, 10, and 11. Clearly, column with larger width tapered ratio, smaller depth tapered ratio, and shorter length has greater rigidity. 


\subsection{Buckling Load Equation}

One of the purposes of this study is to seek a multiplier that can be applied to buckling load of prismatic column to obtain the buckling load of a non-prismatic column. The buckling load of the prismatic section is obtained from Chapter E of AISC 360-16 using average cross section with the same length and boundary conditions as the corresponding non-prismatic column.

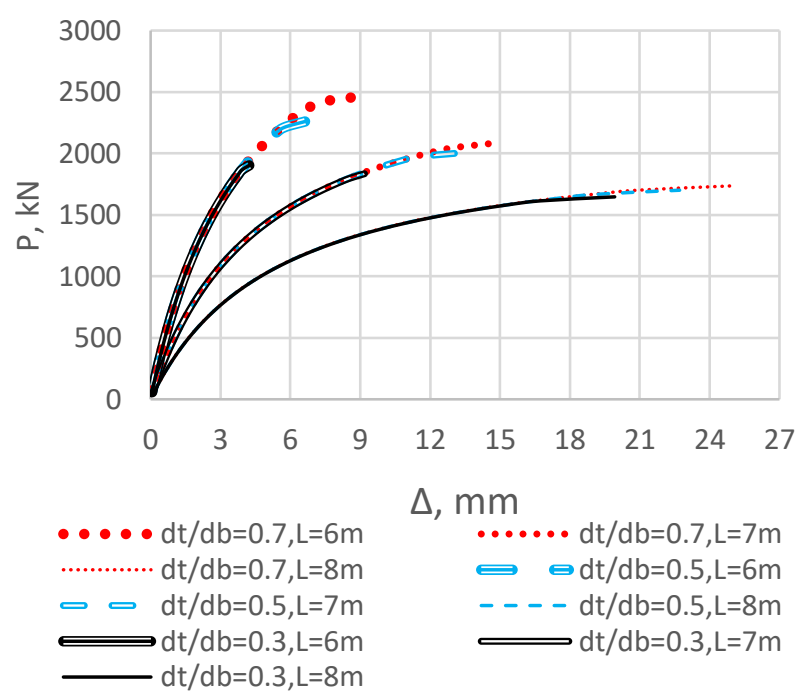

Figure 9. Axial load versus lateral displacement curves for $b_{t} / b_{b}=0.3$

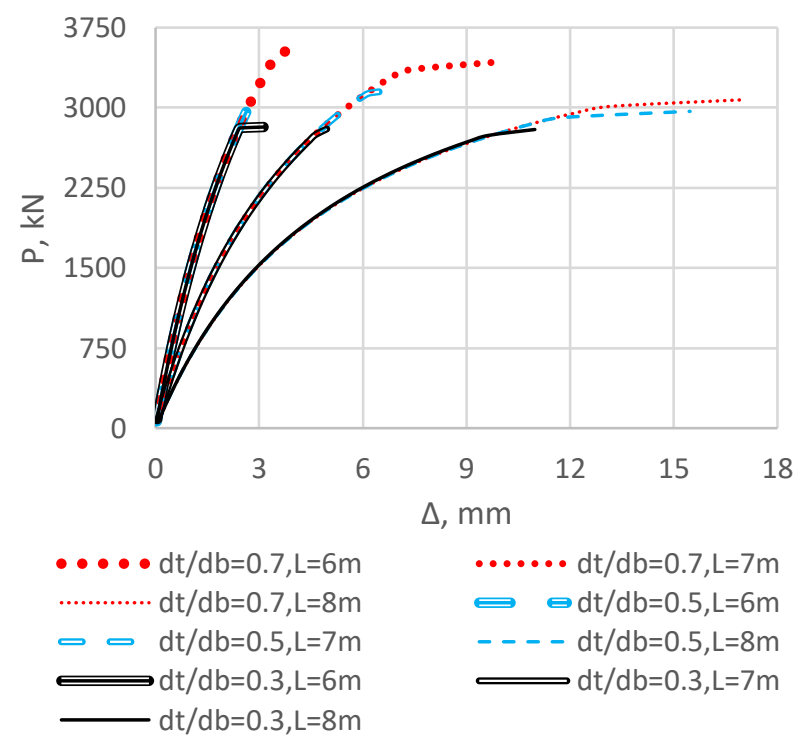

Figure 10. Axial load versus lateral displacement curves for $b_{t} / b_{b}=0.5$

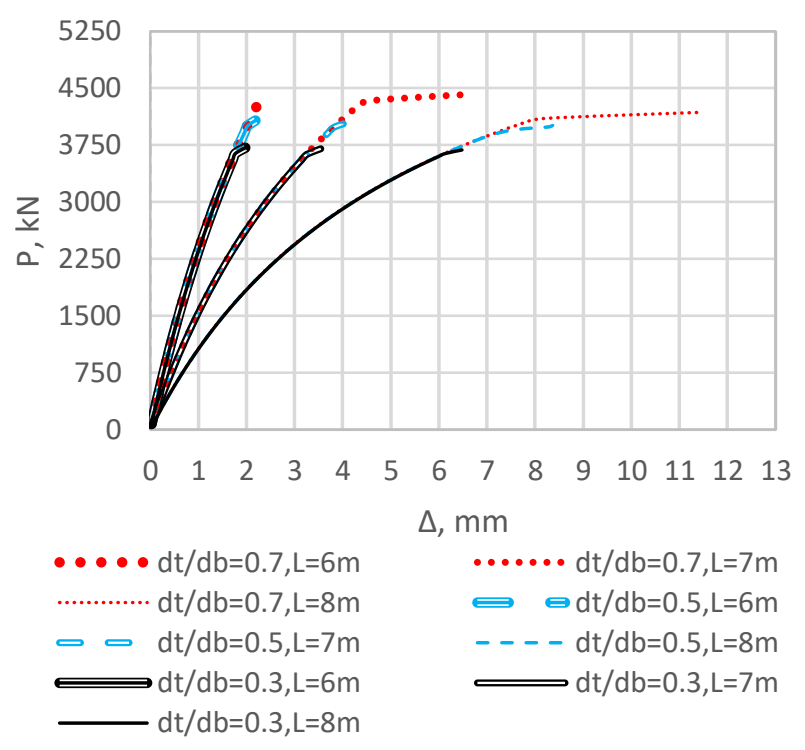

Figure 11. Axial load lateral displacement curves for $b_{t} / b_{b}=0.7$

The multiplier proposed in this study depends on three variables, namely the depth tapered ratio $d_{t} / d_{b}$, width tapered ratio $b_{t} / b_{b}$, and slenderness ratio $\lambda_{\text {avg }}$ of the prismatic section as shown in Table 10. The equation that uses those three variables to obtain the multiplier is obtained using stepwise regression of the finite element results with the coefficient of determination of 95.76\% as Equation (13), (14) and (15).

$$
\begin{aligned}
\frac{P_{\text {crFEA }}=}{P_{\text {cravg }}} & 0.2752+2.1 \frac{b_{t}}{b_{b}}+0.21 \frac{d_{t}}{d_{b}} \\
& -1.215 \frac{b_{t}^{2}}{b_{b}^{2}}-16.50 \frac{1}{\lambda_{\text {avg }}} \\
C_{n p}= & \frac{P_{\text {crFEA }}}{P_{\text {cravg }}} \\
P_{\text {crnp }}= & P_{\text {cravg }} C_{n p}
\end{aligned}
$$

Where $\lambda_{a v g}$ is slenderness ratio of prismatic column section, $P_{\text {cravg }}$ is buckling load of prismatic column section, $P_{\text {crFEA }}$ is buckling load of the corresponding non-prismatic column, and $C_{n p}$ is the multiplier proposed.

In Equation (13), the factor of width tapered ratio $b_{t} / b_{b}$ is as much as ten times the factor of depth tapered ratio $d_{t} / d_{b}$. This signifies the conclusion that width tapered ratio has much more effect on buckling load compared to depth tapered ratio. 
The ratio of buckling load of non-prismatic column from FEA to the buckling load of the corresponding prismatic column section is defined as $C_{n p}$ in Equation (14). Therefore, buckling load of general non-prismatic column section can be obtained by multiplying $C_{n p}$ to buckling load of the corresponding prismatic column section using average cross section (average width and average depth) as shown in Equation (15).

Table 10. Stepwise regression variables

\begin{tabular}{llllll}
\hline$b_{t} / b_{b}$ & $d_{t} / d_{b}$ & $1 / \lambda_{\text {avg }}$ & $\begin{array}{l}P_{\text {crFEA }} \\
(\mathrm{kN})\end{array}$ & $\begin{array}{l}P_{\text {cravg }} \\
(\mathrm{kN})\end{array}$ & $\begin{array}{l}P_{\text {crFEA }} / \\
P_{\text {cravg }}\end{array}$ \\
\hline 0.3 & 0.3 & 0.0134 & 1902 & 2979.0 & 0.64 \\
0.3 & 0.3 & 0.0115 & 1835 & 2676.1 & 0.69 \\
0.3 & 0.3 & 0.0100 & 1647 & 2364.7 & 0.70 \\
0.3 & 0.5 & 0.0131 & 2260 & 3075.4 & 0.73 \\
0.3 & 0.5 & 0.0112 & 2015 & 2749.0 & 0.73 \\
0.3 & 0.5 & 0.0098 & 1701 & 2415.1 & 0.70 \\
0.3 & 0.7 & 0.0128 & 2462 & 3168.7 & 0.78 \\
0.3 & 0.7 & 0.0110 & 2087 & 2818.2 & 0.74 \\
0.3 & 0.7 & 0.0096 & 1736 & 2461.7 & 0.71 \\
0.5 & 0.3 & 0.0157 & 2819 & 3596.1 & 0.78 \\
0.5 & 0.3 & 0.0135 & 2801 & 3327.4 & 0.84 \\
0.5 & 0.3 & 0.0118 & 2796 & 3042.2 & 0.92 \\
0.5 & 0.5 & 0.0154 & 3192 & 3713.63 & 0.86 \\
0.5 & 0.5 & 0.0132 & 3171 & 3425.00 & 0.93 \\
0.5 & 0.5 & 0.0115 & 2966 & 3119.74 & 0.95 \\
0.5 & 0.7 & 0.0151 & 3559 & 3828.80 & 0.93 \\
0.5 & 0.7 & 0.0129 & 3423 & 3519.74 & 0.97 \\
0.5 & 0.7 & 0.0113 & 3073 & 3194.00 & 0.96 \\
0.7 & 0.3 & 0.0181 & 3716 & 4171.90 & 0.89 \\
0.7 & 0.3 & 0.0155 & 3703 & 3933.92 & 0.94 \\
0.7 & 0.3 & 0.0135 & 3687 & 3676.15 & 1.00 \\
0.7 & 0.5 & 0.0177 & 4086 & 4304.47 & 0.95 \\
0.7 & 0.5 & 0.0152 & 4070 & 4049.85 & 1.00 \\
0.7 & 0.5 & 0.0133 & 4010 & 3774.72 & 1.06 \\
0.7 & 0.7 & 0.0174 & 4449 & 4435.25 & 1.00 \\
0.7 & 0.7 & 0.0149 & 4422 & 4163.56 & 1.06 \\
0.7 & 0.7 & 0.0131 & 4184 & 3870.69 & 1.08 \\
\hline & & & & &
\end{tabular}

\section{CONCLUSIONS}

This study shows that buckling load of nonprismatic I-section depends on the width tapered ratio of both ends, the depth tapered ratio of both ends, and the average slenderness ratio. Larger width tapered ratio of both ends has larger buckling load and the column become more rigid but less ductile. As width tapered ratio increases from 0.3 to 0.7 , the buckling load increases between $84.7 \%$ to $141.1 \%$. Larger depth tapered ratio of both ends has larger buckling load but neither rigidity nor ductility is affected. As the depth tapered ratio of both ends increases from 0.3 to 0.7 , buckling load increases between $5.4 \%$ to $29.4 \%$. Larger average slenderness ratio has smaller buckling load and the column becomes more ductile.

This study proposed a multiplier $C_{n p}$ that can be applied to buckling load of prismatic column to obtain buckling load of corresponding nonprismatic section. The prismatic column is a column with the average width and depth of the non-prismatic column. The multiplier depends on the width tapered ratio, depth tapered ratio, and slenderness ratio of the column. Although it is unusual to derive an equation from the analytical result, hence experimental result is usually used, because of there is no experimental result yet, regression of FEA result is conducted to produce $C_{n p}$. Therefore, further study especially experimental study is needed to verify the proposed $C_{n p}$ and also to achieve more accurate and reliable result of $C_{n p}$.

It should be noted that the proposed multiplier $C_{n p}$ was developed for the depth ratio between 0.3 to 0.7 , width tapered tapered ratio between 0.3 to 0.7 , and slenderness ratio between 55.39 to 104.33. Therefore, the use of the equation to compute $C_{n p}$ for any value of those variables outside these ranges needs further verifications.

Consideration of residual stress, other type of buckling, and another boundary conditions are interesting aspects for further study of axially loaded non-prismatic I-sections.

\section{ACKNOWLEDGEMENT}

The authors wish to acknowledge the Structural Laboratory of Parahyangan Catholic University for the use of the finite element software ANSYS. 


\section{REFERENCES}

AL-Shareef, H. (2014) 'Non-Linear Buckling Analysis of Non-Prismatic Steel Columns Subjected to Axial Compression Loads', 6(2), pp. 54-75.

American Institute of Steel Construction (2016) Specification for Structural Steel Buildings. Chicago: AISC Committee on Specifications.

Bjorhovde, R., 1972. Deterministic and Probabilistic Approaches to The Strength of Steel Columns, USA: Doctoral Disertation. Civil Engineering Departmen. Leigh University.

EN 1993-1-1 (2005) Eurocode 3: Design of steel structures - Part 1-1: General rules and rules for buildings, Eurocode 3.

Galambos, T. V. and Surovek, A. E. (2008) Structural Stability of Steel: Concepts and Applications for Structural Engineers, Structural Stability of Steel: Concepts and Applications for Structural Engineers. doi: 10.1002/9780470261316.

Hassan Ibrahim, T. (2017) Buckling Loads and Effective Length Factor for Non-Prismatic Columns, Journal of Engineering, 10, pp. 134-145

ANSYS Inc. (2007) Elements Reference ANSYS Release 11.0, USA: SAS IP

Kaehler, R. C., White, D. W. and Kim, Y. . (2011) Design Guide 25 - Frame Design Using TaperedwebMembers, USA: AISC

Kucukler, M. and Gardner, L. (2018) 'Design of laterally restrained tapered-websteel structures through a stiffness reduction method', Journal of Constructional Steel Research, pp. 63-76. doi: 10.1016/j.jcsr.2017.11.014.

Lee, G., Morrell, M.L. \& Ketter, R.L. (1972) Design of tapered members. New York NY: Welding Research Council.

Marques, L. et al. (2014) 'Extension of EC3-1-1 interaction formulae for the stability verification of tapered beam-columns', Journal of Constructional Steel Research, 100, pp. 122-135. doi: 10.1016/j.jcsr.2014.04.024.

Riahi, H. T. et al. (2012) Buckling Analysis of NonPrismatic Columns Using Slope-Deflection Method. Lisboa, World Conference on Earthquake Engineering

Salmon, C. G., Johnson, J. E. and Malhas, F. A. (2009) Steel structures: design and behavior: emphasizing load and resistance factor design. Pearson/Prentice Hall.

Tankova, T. et al. (2018) 'Experimental buckling behaviour of web tapered I-section steel columns', Journal of Constructional Steel Research. doi: 10.1016/j.jcsr.2018.04.015.

Timosenko, S. P. (1878-1972). and Gere, J. M. (1925-2008). (1963) Theory of elastic stability. 2. ed. Auckland: McGraw-Hill.

Ziemian, R. D. (ed.) (2010) Guide to Stability Design Criteria for Metal Structures. Hoboken, NJ, USA: John Wiley \& Sons, Inc. doi: 10.1002/9780470549087. 
[This page is intentionally left blank] 